\title{
Karakteristik Mangrove di Muara Sungai Timur Kawasan Laguna Segara Anakan, Kabupaten Cilacap Jawa Tengah
}

\author{
Raditya Rizki Ananta*, Nirwani Soenardjo, Rini Pramesti \\ Departemen IImu Kelautan, Fakultas Perikanan dan IImu Kelautan Universitas Diponegoro \\ Jl. Prof. H. Soedarto S.H, Tembalang Semarang, Jawa Tengah 50275 Indonesia \\ ${ }^{\star}$ Corresponding author, e-mail raditya.adit61@gmail.com
}

\begin{abstract}
ABSTRAK: Ekosistem mangrove adalah komunitas tumbuhan tropis yang berada di daerah tepi pantai yang memiliki kemampuan adaptasi pada perairan asin di wilayah intertidal yang dipengaruhi oleh pasang surut air laut. Struktur komunitas mangrove merupakan salah satu parameter dalam menentukan kondisi mangrove. Kawasan ekosistem mangrove yang memiliki karakteristik dinamis komposisi jenis mangrove terdapat di Segara Anakan. Akan tetapi memiliki penurunan luasan hutan mangrove. Hal ini adanya beragam faktor kondisi lingkungan di Segara Anakan, sehingga menyebabkan variabilitas mangrove wilayah Segara Anakan berbeda. Namun kondisi terkini belum banyak dilakukan dalam suatu penelitian sehingga dibutuhkan informasi ilmiah terkini untuk mengetahui komposisi jenis mangrove. Untuk mengatasi hal tersebut maka dilakukan penelitian struktur komunitas untuk mengetahui kondisi ekologi mangrove di Segara Anakan. Tujuan penelitian ini adalah menggambarkan kondisi struktur komunitas mangrove di muara timur Segara Anakan. Lokasi penelitian berada di muara sungai bagian Timur (Sungai Donan). Metode yang digunakan dalam penelitian ini adalah metode deskriptif. Penentuan titik pengambilan data atau sampel di setiap lokasi dilakukan dengan teknik purposive sampling. Selain itu, digunakan teknik transek kuadrat 10x10 m dan Hemispherical Photography. Hasil penelitian menunjukkan kerapatan pohon sebesar $90,6 \times 10^{1} /$ ha. Kerapatan sapling rata-rata bernilai $1023 \times 10^{1} /$ ha. Kerapatan seedling bernilai $1746 \times 10^{1}$ /ha di Muara Timur. Tutupan kanopi komunitas mangrove memiliki persentase kurang dari $75 \%$. Tinggi dan diameter pohon didapatkan sebesar 5,97 $\mathrm{m}$ dan 3,1 cm. Spesies mangrove yang ditemukan di dalam plot berjumlah 10 spesies mangrove yaitu Rhizophora apiculata, Bruguiera gymnorrhiza, Aegiceras corniculatum, Avicennia marina, Avicennia alba, Ceriops tagal, Ceriops decandra, Sonneratia caseolaris, Sonneratia alba, Scyphiphora hydrophyllacea, Xylocarpus moluccensis, Xylocarpus granatum, Talipariti tiliaceum, dan Nypa fruticans.
\end{abstract}

Kata kunci: Struktur komunitas; Mangrove; Segara Anakan; Komposisi spesies; Muara Sungai

\section{Mangrove Characteristic in East River Mouth, Laguna Segara Anakan, Cilacap District, Central Java}

ABSTRACT: Mangrove ecosystems are communities of tropical plants located on the coast that have the ability to adapt to salty waters in intertidal areas which are affected by tides. Mangrove community structure is one of the parameters in determining mangrove condition. Mangrove ecosystem areas that have dynamic characteristics of mangrove species composition are found in Segara Anakan. However, it has decreased the area of mangrove forests. This is because of various environmental conditions in Segara Anakan, causing variability of mangroves in the Segara Anakan area to be different. However, recent conditions have not been carried out in many studies, so the latest scientific information is needed to determine the species composition of mangroves. To overcome this, a community structure research was conducted to determine the ecological conditions of mangroves in Segara Anakan. The purpose of this study was to describe the condition of the mangrove community structure in the eastern estuary of Segara Anakan. The research location is in the mouth of the eastern river (Donan River). The method used in this research is descriptive method. Determination of data collection points or samples at each location was done by using purposive sampling technique. In addition, the $10 \times 10 \mathrm{~m}$ quadratic transect technique and Hemispherical Photography were used. The results showed the tree density was $90.6 \mathrm{ind} / \mathrm{ha}$. Sapling 
averaged $1023 \mathrm{ind} / \mathrm{ha}$. The density seedling is $1746 \mathrm{ind} / \mathrm{ha}$ in Muara Timur. The canopy cover of the mangrove community has a percentage of less than 75\%. The tree height and diameter were 5.97 $m$ and $3.1 \mathrm{~cm}$ respectively. There are 10 mangrove species found in the plot, namely Rhizophora apiculata, Bruguiera gymnorrhiza, Aegiceras corniculatum, Avicennia marina, Avicennia alba, Ceriops tagal, Ceriops decandra, Sonneratia caseolaris, Sonneratia alba, Scyphiphora hydrophyllacea, Xylocarpus moluccensis, Xylocarpus granatum, Talipariti tiliaceum, and Nypa fruticans.

Keywords: Community structure; Mangrove; Segara Anakan; Species Composition; River Mouth

\section{PENDAHULUAN}

Ekosistem mangrove memiliki fungsi sebagai tempat hidup, berkembang biak bagi bota laut, dan dapat melindungi pemukiman dari angin kencang (Warfield \& Leon, 2019; Noor et al., 2006). Struktur komunitas mangrove merupakan parameter dalam menentukan kondisi mangrove di suatu kawasan. Struktur komunitas ini banyak digunakan dan bermodifikasi dengan hemispherical photography untuk menganalisa tutupan kanopi. Indikator yang dihitung pada struktur komunitas yaitu, kerapatan, diameter, tinggi, Indeks Nilai Penting (INP), dan persentase tutupan kanopi. Kerapatan mangrove diperoleh dari jumlah tegakan dalam satu luasan. Indeks Nilai Penting (INP) berpengaruh pada setiap jenis mangrove yang diukur dalam satu area. Persentase tutupan kanopi dapat menentukan kondisi mangrove (Dharmawan \& Pramudji, 2017).

Segara Anakan mempunyai luasan, struktur komunitas dan komposisi jenis mangrove yang dinamis. Purwanto et al. (2014), luas mangrove di kawasan ini mencapai 6.716 ha dan menurun sebesar 1284 ha pada tahun 2013. Wilayah muara bagian barat (Sungai Cikonde, Citanduy, dan Cibeureum) memiliki tingkat sedimentasi menyebabkan luasannya menurun dari 4072 ha menjadi 3500 ha. Faktor ini disebabkan laju sedimentasi. Peran Sungai Citanduy sekitar $80 \%$ seluruh aliran air tawar yang menuju Segara Anakan, sehingga sedimentasi muara bagian barat lebih dibandingkan muara tengah (Sungai Sapuregel) dan muara timur (Sungai Donan) (Dewi et al., 2016). Faktor ini dapat mempengaruhi kondisi perairan. Hal tersebut menyebabkan komposisi jenis mangrove berbeda di tiga wilayah.

Penelitian terdahulu (Yuwono et al., 2007; Hilmi et al., 2015; Koswara et al., 2017) menggambarkan Segara Anakan mengalami perubahan luasan hutan mangrove dan menurunnya komposisi jenis mangrove dengan beragam faktor diantaranya sedimentasi dan penebangan liar yang dijadikan sebagai tambak. Perlu adanya penelitian secara berkala berkaitan komposisi jenis mangrove di wilayah tersebut. Penelitian ini bertujuan untuk menggambarkan struktur komunitas mangrove di Segara Anakan.

\section{MATERI DAN METODE}

Materi penelitian yang digunakan adalah vegetasi mangrove pada kawasan Segara Anakan, Kabupaten Cilacap, Jawa Tengah. Materi vegetasi meliputi data diameter batang, tinggi pohon, dan tutupan kanopi. Metode penelitian yang digunakan adalah metode deskriptif. Metode ini bertujuan untuk melihat gambaran dan sifat populasi ekosistem mangrove. Penelitian dilaksanakan pada bulan Agustus - Desember 2019. Penentuan titik pengambilan sampel menggunakan teknik purposive sampling. Titik pengambilan sampel berada di Muara Timur (Gambar 1).

Teknik pengambilan data vegetasi mengacu pada Dharmawan \& Pramudji (2017), yaitu teknik plot sampling. Teknik ini dilakukan pada transek kuadran ukuran $10 \mathrm{~m} \times 10 \mathrm{~m}$ meliputi keliling atau diameter (pohon, sapling, dan seedling). Pengambilan sampel pohon dilakukan dalam plot ukuran $10 \mathrm{~m} \times 10 \mathrm{~m}$. Diameter batang diukur pada ketinggian setinggi dada manusia dewasa (Diameter at Breast Height) $(\mathrm{DBH})$ atau $\pm 1,3 \mathrm{~m}$. Kategori pohon yang diukur memiliki DBH (diameter $\geq 4 \mathrm{~cm}$ atau keliling batang $\geq 16 \mathrm{~cm}$ ) meliputi jumlah tegakan mangrove, diameter pohon, dan spesies pohon. Ashton \& Macintosh (2002), kategori sapling memiliki diameter batang $<4 \mathrm{~cm}$ dan tingginya $>1 \mathrm{~m}$ dari plot $10 \mathrm{~m}$ x $10 \mathrm{~m}$. Dharmawan dan Pramudji (2017), sampel semai (seedling) dilakukan pada 
plot ukuran $10 \mathrm{~m} \times 10 \mathrm{~m}$ dan ketinggian < $1 \mathrm{~m}$. Sampel yang diambil meliputi jenis spesies dan jumlah seedling. Pengambilan sampel tutupan kanopi dilakukan dengan Hemispherical photography. Hasil data diameter digunakan untuk mengetahui kerapatan. Hasil tutupan kanopi untuk menentukan persentase tutupan kanopi mangrove.
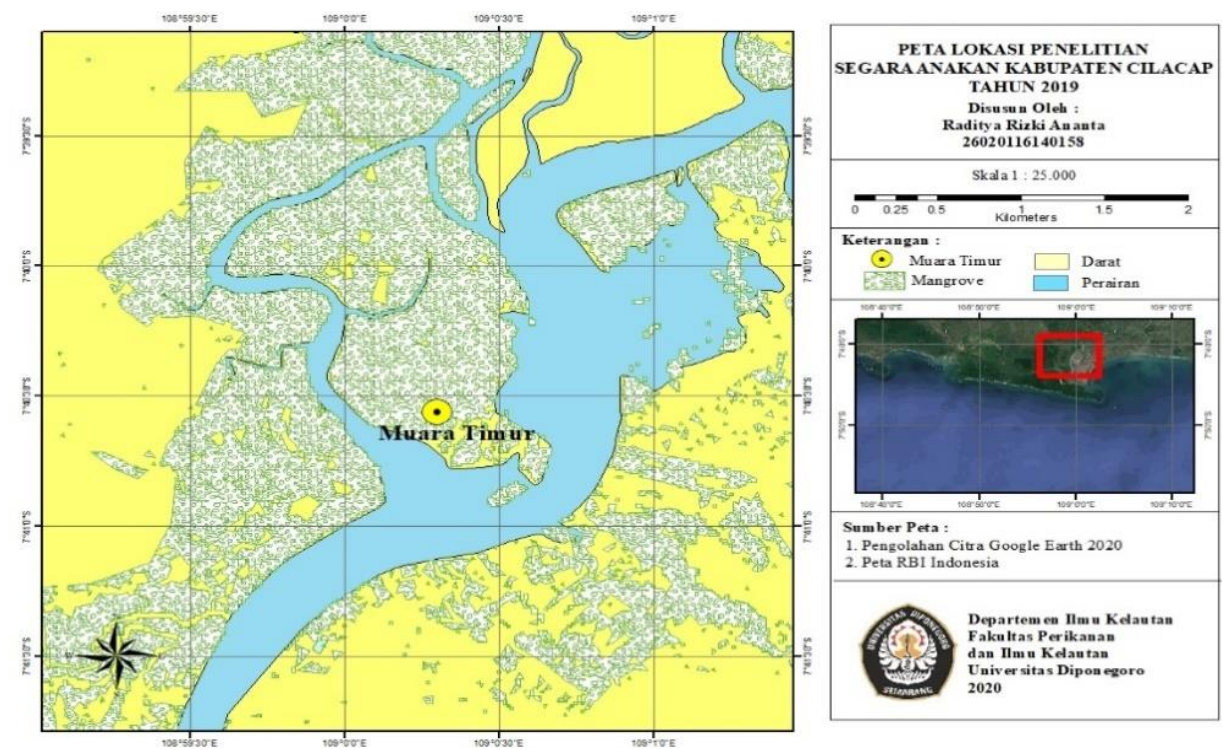

Gambar 1. Lokasi penelitian di Kawasan Segara Anakan

\section{HASIL DAN PEMBAHASAN}

Penelitian yang dilakukan berupa struktur komunitas mangrove Muara Sungai Timur Segara Anakan. Lokasi Muara Sungai Timur Segara Anakan berada di area Sungai Donan. Lokasi tersebut memiliki kondisi yang cukup beraneka ragam yaitu kawasan permukiman, dampak sedimentasi, dan kawasan ekosistem mangrove yang cukup baik. Luas hutan mangrove Segara Anakan sebesar 6.126 ha (Ismail et al., 2018).
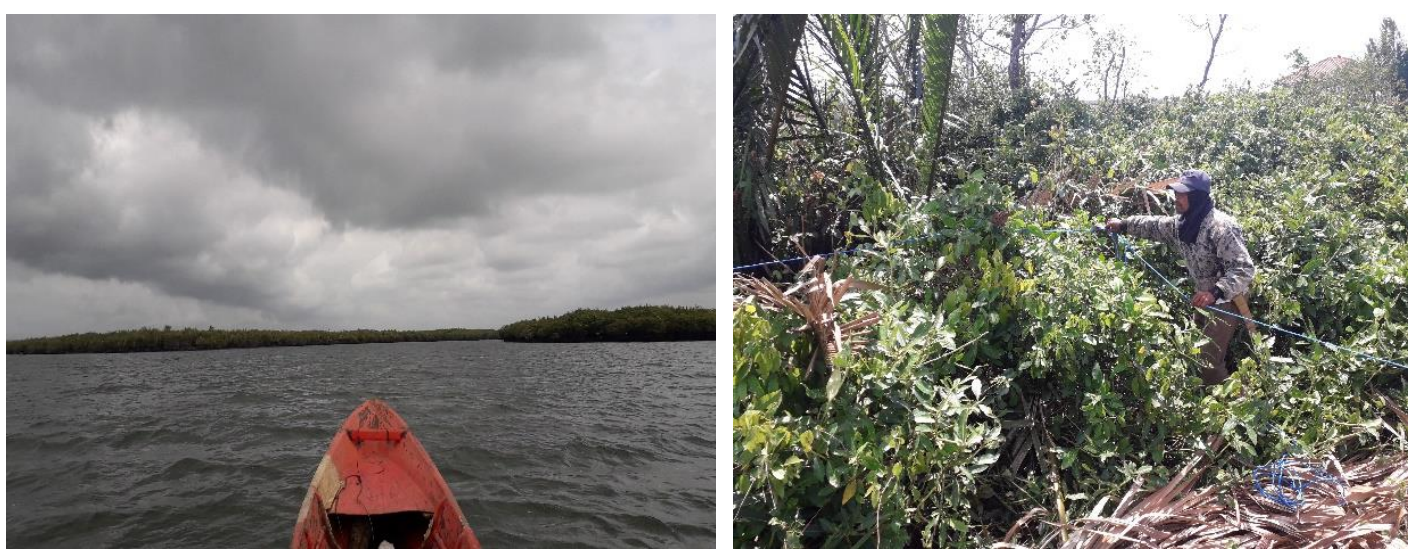

Gambar 2. Kondisi Ekosistem Mangrove di lokasi penelitian

Pada penelitian ini didapatkan komposisi jenis berjumah 10 spesies yang terdiri dari Rhizophora apiculata, Bruguiera gymnorrhiza, Aegiceras corniculatum, Avicennia marina, Avicennia alba, Ceriops tagal, Ceriops decandra, Sonneratia caseolaris, Sonneratia alba, Scyphiphora hydrophyllacea, Xylocarpus moluccensis, Xylocarpus granatum, Talipariti tiliaceum, dan Nypa fruticans. Seluruh spesies tersebut termasuk dalam tiga famili dari kategori mayor (Avicenniaceae, Rhizophoraceae, dan Sonneratiaceae), dua famili dari kategori minor (Meliaceae dan Myrsinaceae) (Tabel 1). Banyaknya jenis famili Rhizophoraceae yang ditemukan disebabkan kehadiran jenis ini 
lebih banyak didapatkan dibandingkan famili lainnya. Hasil ini dapat diartikan Segara Anakan memiliki variabilitas yang cukup tinggi. Selain itu substrat yang ditemukan pada lokasi ini lumpur berpasir yang cocok dengan pertumbuhan untuk mangrove yang didapatkan pada lokasi tersebut. Faktor ini diduga cocok dengan pertumbuhan mangrove. Darmadi (2012), mangrove akan cepat beradaptasi dan tumbuh dengan tipe substrat lumpur berpasir. Menurut Akbar et al. (2017), jenis mangrove yang terbentuk dapat disebabkan oleh aspek fisiologis, biologis, dan ekologi. Jumlah spesies yang ditemukan di penelitian ini lebih rendah dibandingkan di Merauke (Siringoringo et al., 2019). Sedangkan penelitian yang dilakukan di Pulau Komodo dan Mentawai (Hadi et al., 2019; Samsuardi et al., 2019) memiliki jumlah yang sangat sedikit dibandingkan penelitian di Segara Anakan.

Tabel 1. Distribusi tingkat tegakan setiap jenis mangrove di lokasi penelitian.

\begin{tabular}{lccccc}
\hline \multirow{2}{*}{ No } & \multirow{2}{*}{ Famili dan kategori } & Spesies & \multicolumn{3}{c}{ Kategori } \\
\cline { 3 - 5 } & Rhizophoraceae (Mayor) & Rhizophora apiculata & + & + & + \\
\hline 1 & Rhizophoraceae (Mayor) & Bruguiera gymnorrhiza & + & + & + \\
2 & Ceriops tagal & - & + & + \\
3 & Rhizophoraceae (Mayor) & Ceriops decandra & - & - & + \\
4 & Rhizophoraceae (Mayor) & Avicennia marina & + & + & + \\
5 & Avicenniaceae (Mayor) & Avicennia alba & - & - & + \\
6 & Avicenniaceae (Mayor) & Sonneratia caseolaris & - & - & + \\
7 & Sonneratiaaceae (Mayor) & Sonneratia alba & + & - & + \\
8 & Sonneratiaaceae (Mayor) & Xylocarpus granatum & - & - & + \\
9 & Meliaceae (Minor) & Aegiceras corniculatum & + & + & + \\
10 & Myrsinaceae (Minor) & Aegicerang &
\end{tabular}

Keterangan: (+) dijumpai; (-) tidak dijumpai;

Sumber: Penamaan nama berdasarkan Kitamura et al. (1997).

Kerapatan pohon mangrove di Segara Anakan termasuk kategori rendah sebesar 90,6x101/ha. Keputusan Menteri Lingkungan Hidup No 201 tahun 2004, kerapatan mangrove di Segara Anakan termasuk kriteria rusak/jarang dimana memiliki kerapatan $<1000 \mathrm{ind} / \mathrm{ha}$. Rendahnya kerapatan pohon dipengaruhi oleh laju sedimentasi yang cukup tinggi di Segara Anakan yang memiliki karakteristik mangrove muara sungai dan delta. Sihombing et al. (2017), semakin tinggi laju sedimentasi maka semakin rendah kerapatan mangrove, sedangkan laju sedimentasi yang rendah akan meningkatkan kerapatan mangrove. Selain secara oleh faktor alami, penebangan liar juga dapat menurunkan jumlah tegakan pohon dalam komunitas (Purwanto et al., 2019). Penelitian ini menemukan kerapatan pohon yang lebih rendah dibandingkan penelitian yang dilakukan Rahmawati et al. (2019) di Bintan (3.583 \pm 219 ind/ha), Sedangkan nilai kerapatan yang dilaksanakan di Desa Bedono memiliki nilai dengan rentang 600-700 ind/ha (Sihombing et al., 2017). Nilai tersebut lebih rendah dengan penelitian yang dilakukan di lokasi Segara Anakan.

Kerapatan sapling $\left(1023 \times 10^{1 / h a}\right)$ dan seedling $\left(1746 \times 10^{1 / h a}\right)$ ditemukan memiliki nilai yg baik. Pertumbuhan sapling dan seedling yang tinggi menunjukan adanya regenerasi mangrove yang sangat baik. Syamsuddin et al. (2019), kawasan dengan nilai kerapatan anakan tinggi memiliki penerus atau regenerasi yang cukup baik kedepannya dan kelestarian jenis-jenis pohon akan berlangsung lama. Selain itu, keberadaan sampah yang cukup sedikit diduga menjadi salah satu faktor tingginya nilai sapling dan seedling di wilayah ini. Menurut Petra et al. (2012), lokasi yang memiliki sapling dan seedling yang rendah dapat diindikasikan daerah tersebut tertutup sampah sehingga dapat berdampak pada tingkat pertumbuhan sapling dan seedling. Hasil yang didapatkan pada penelitian ini lebih baik dibandingkan di Tual dengan nilai sapling sebesar 407 ind/ha dan seedling sebesar 3033 ind/ha (Prayudha et al., 2019). Akan tetapi nilai penelitian di Segara Anakan lebih rendah dibandingkan di Bali (Hermawan et al., 2014).

Nilai persentase tutupan kanopi didapatkan sebesar $74.62 \pm 5,3 \%$. Nilai tersebut dapat dikategorikan baik (Keputusan Menteri Lingkungan Hidup No 201, 2004). Tinggi rendahnya 
persentase tutupan kanopi akan berpengaruh pada pertumbuhan sapling dan seedling. Hal ini berbanding lurus dengan nilai kerapatan sapling maupun seedling yang dapat dikategorikan sangat baik. Persentase yang baik di Muara Timur diduga didominansi jenis Rhizophora apiculata. Schaduw (2019), persentase tutupan kanopi yang didominasi oleh jenis Rhizophora sp. bernilai tinggi dibandingkan jenis Avicennia sp. yang mempunyai persentase kecil, dimana memiliki lebar daun yang kecil. Persentase tutupan kanopi mangrove dilakukan di daerah Biak dan Anambas memiliki persentase yang lebih tinggi dibandingkan di Segara Anakan (Dharmawan, 2019; Sari et al., 2019). Siringoringi (2016), penelitian di Nias Utara memiliki nilai $(55,98 \pm 28,69)$ yang lebih kecil dibandingkan di Segara Anakan.

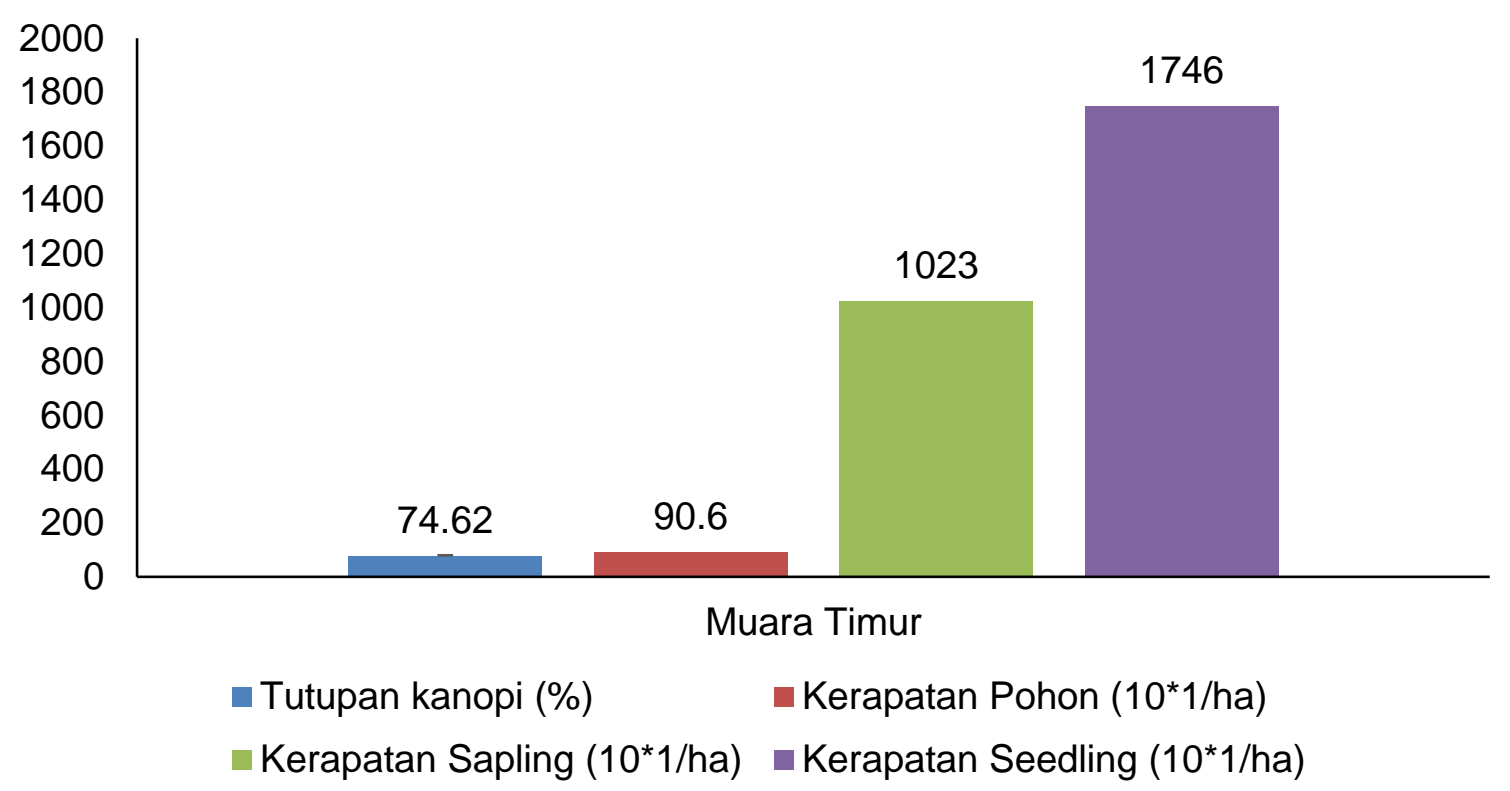

Gambar 3. Kerapatan tegakan pohon, sapling, seedling dan tutupan kanopi mangrove

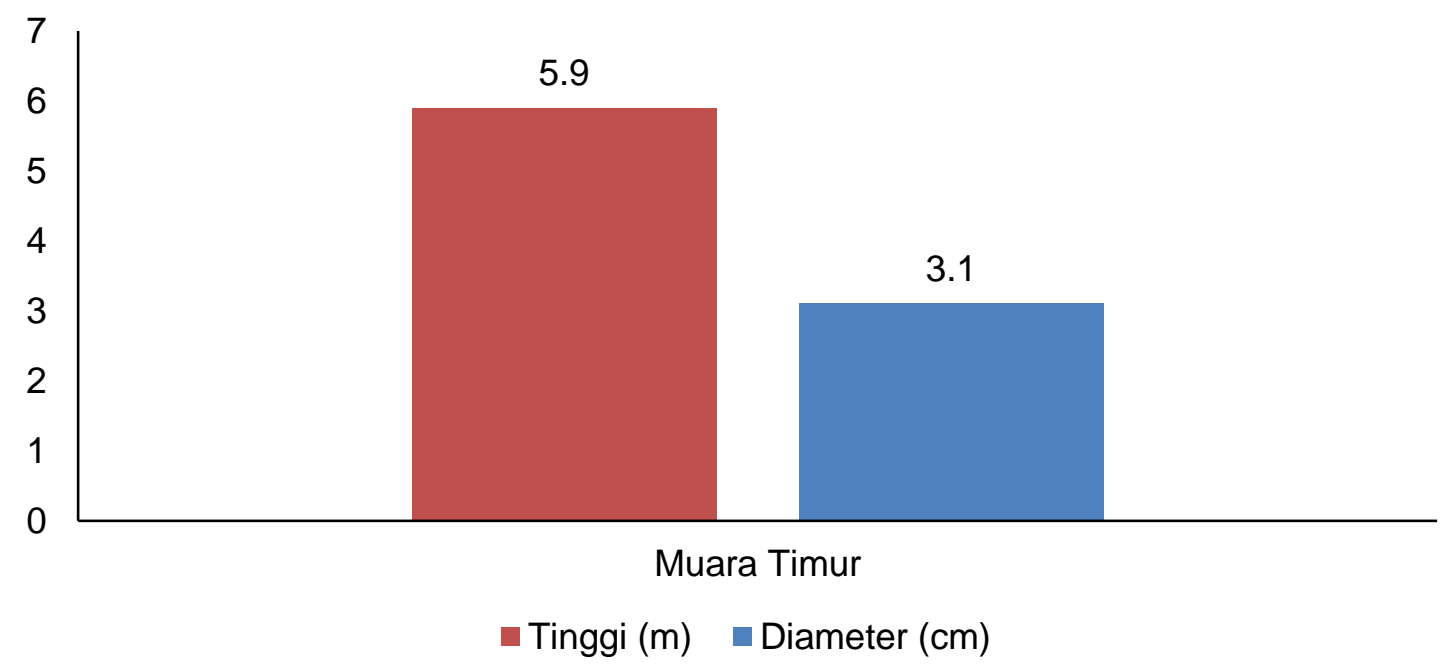

Gambar 4. Ukuran morfometrik tinggi dan diameter tegakan mangrove di Segara Anakan.

Jumlah sapling dan seedling di stasiun Muara Timur memiliki nilai yang cukup tinggi. Hal ini berbanding terbalik dengan nilai ukuran morfometrik tinggi dan diameter (Gambar 4), dikarenakan adanya kompetisi mangrove yang tinggi. Kerapatan yang tinggi menyebabkan kompetisi mangrove akan semakin meningkat, sehingga ketersediaan ruang dan nutrisi untuk pertumbuhan diameter maupun tinggi akan relatif kecil begitupun sebaliknya. Dewi et al. (2017), kerapatan mangrove yang 
jarang umumnya mendapat kesempatan untuk penyerapan hara yang lebih tinggi dan kompetisi ruang yang lebih rendah untuk pertumbuhan mangrove. Selain itu ukuran morfometrik yang kecil pada penelitian ini diduga adanya degradasi mangrove dan faktor antropogenik. . Utama et al. (2019), Daerah yang mengalami penebangan yang cukup tinggi akan memiliki pohon yang ukurannya relatif lebih kecil. Pengaruh persentase tutupan kanopi yang tinggi diduga mempengaruhi proses fotosintesis. Sadono (2018), Peran kanopi mangrove yang mempengaruhi proses fotosintesis, proses tersebut didistribusikan untuk pertumbuhan diameter batang maupun tinggi pohon.

\section{KESIMPULAN}

Komposisi jenis mangrove yang dtemukan 10 spesies yaitu Rhizophora apiculata, Bruguiera gymnorrhiza, Aegiceras corniculatum, Avicennia marina, Ceriops tagal, Sonneratia alba, $C$. decandra, S. caseolaris, A. alba, Scyphiphora hydrophyllacea, Xylocarpus moluccensis, $X$. granatum, Talipariti tiliaceum, dan Nypa fruticans. Muara Timur memliki kerapatan (pohon, seedling, dan sapling) yang cukup baik. Ukuran morfometrik diameter $(3,1 \mathrm{~cm})$ dan tinggi $(5,97 \mathrm{~m})$ pada penelitian memiliki nilai yang baik. Persentase tutupan kanopi lokasi penelitian termasuk sedang $(<75 \%)$. Kondisi ekosistem pada wilayah Segara Anakan tergolong cukup baik dalam komposisi jenis mangrove. Diharapkan dengan adanya penelitian dapat dijadikan referensi bagi pemerintah dan warga setempat untuk melestarikan mangrove Segara Anakan menjadi lebih baik.

\section{DAFTAR PUSTAKA}

Akbar, N., Marus, I., Haji, I., Abdullah, S., Umalekhoa, S., Ibrahim, F.S., Ahmad, M., Ibrahim, A., Kahar, A. \& Tahir, I., 2017. Struktur Komunitas Hutan Mangrove di Teluk Dodinga, Kabupaten Halmahera Barat Provinsi Maluku Utara. Jurnal Enggano, 2(1):78-89. DOI : 10.31186/ jenggano.2.1.78-89.

Ashton, E.C. \& Macintosh D.J. 2002. Preliminary Assessment of the plant Diversity and Community Ecology of The Sematan Mangrove Forest, Serawa, Malaysia. Universitas of Aarthus. Denmark. Forest Ecology and Management, 166(2002):111-129. DOI: 10.1016/S0378-1127(01)00673-9.

Darmadi, D., Lewaru, M. W., \& Khan, A. M. 2012. Struktur Komunitas Vegetasi Mangrove Berdasarkan Karakteristik Substrat di Muara Harmin Desa Cangkring Kecamatan Cantigi Kabupaten Indramayu. Jurnal Perikanan dan Kelautan Unpad, 3(3): 125170.

Dewi, R., M. Zainuri., S. Anggoro dan T. Winanto. 2016. Analisis Perubahan Lahan Kawasan Laguna Segara Anakan Selama Periode Waktu (1978 - 2016) Menggunakan Satelit Landsat Multitemporal. Jurnal Omni Akuatika., 12(3):144-14. DOI: 10.20884/1.oa.2016.12.3.209.

Dharmawan, I.W.E. \& Pramudji. 2017 Kajian Kondisi Kesehatan Ekosistem Mangrove di Kawasan Pesisir Kabupaten Lampung Selatan. COREMAP-CTI Pusat Penelitian Oseanografi, LIPI. Jakarta.

Dharmawan, I.W.E. \& Widyiastuti, A. 2017. Pristine Mangrove Community in Wondama Gulf, West Papua, Indonesia. Marine Research In Indonesia., 42(2):73-78.

Hadi, T.A., Suharsono, Giyanto, \& Ulumuddin, Y.I. 2019. Monitoring Kesehatan Terumbu Karang dan Ekosistem Terkait di Taman Nasional Komodo dan Sekitarnya, Nusa Tenggara Timur. COREMAP-CTI Pusat Penelitian OSeanografi, LIPI. Jakarta.

Hilmi, E., Siregar, A. S., \& Febryanni, L. 2015. Struktur komunitas, zonasi dan keanekaragaman hayati vegetasi mangrove di Segara Anakan Cilacap. Jurnal Omni Akuatika., 11(2):20-32. DOI: 10.20884/1.oa.2015.11.2.36

Keputusan Menteri Negara Lingkungan Hidup Nomor 201 Tahun 2004 Tentang Kriteria Baku dan Pedoman Penentuan Kerusakan Mangrove.

Koswara, S.D., Ardli, E.R., \& Yani, E. 2017. The Monitoring of Mangrove Vegetation Community Structure in Segara Anakan Cilacap for the Period of 2009 And 2015. Scripta Biologica., 4(2): 113-118. DOI: 10.20884/1.sb.2017.4.2.414.

Noor, Y.R., Khazali, M. dan Suryadiputra, I.N.N. 2006. Panduan Pengenalan Mangrove di Indonesia. PKA/WI-IP, Bogor, $220 \mathrm{hlm}$.

Purwanto, A.D., Asriningrum, W., Winarso, G. dan Parwati, E. 2014. Analisis Sebaran dan Kerapatan 
Mangrove Menggunakan Citra Landsat 8 Di Segara Anakan, Cilacap. Prosiding Seminar Nasional Penginderaan Jauh LAPAN.

Purwanto, A.D., Winarso, G. dan Julzarika, A. 2019. Identifikasi Mangrove Sejati Menggunakan Metode Obia Berdasarkan Citra Landsat 8 Oli dan Landsat 7 ETM+ Studi Kasus: Kawasan Mangrove Segara Anakan, Cilacap. Prosiding Seminar Nasional Geomatika.

Sadono, R. 2018. Prediksi Lebar Tajuk Pohon Dominan pada Pertanaman Jati Asal Kebun Benih Klon di Kesatuan Pemangkuan Hutan Ngawi, Jawa Timur. Jurnal Ilmu Kehutanan, 12:127-141. DOI: $10.22146 /$ jik.40143.

Samsuardi, Bukhari, \& Yennafri. 2019. Monitoring Kesehatan Terumbu Karang dan Ekosistem Terkait di Taman Wisata Perairan (TWP) Selat Bunga Laut, Kabupaten Kepulauan Mentawai. COREMAP-CTI Pusat Penelitian Oseanografi, LIPI. Jakarta.

Schaduw, J.N.W. 2019. Struktur Komunitas dan Persentase Penutupan Kanopi Mangrove Pulau Salawati Kabupaten Kepulauan Raja Ampat Provinsi Papua Barat. Majalah Geografi Indonesia, 33(1):26-34. DOI: 10.22146/mgi.34745

Sihombing, Y.H., Muskananfola, M.R. dan A'in, C. 2017. Pengaruh Kerpatan Mangrove terhadap Laju Sedimentasi di desa Bedono, Demak. Jurnal of Maquares, 6(4): 536-545.

Siringoringo, R.M., Abrar, M., Sari, N.W.P., dan Hukom, F.D. 2019. Monitoring Kesehatan Terumbu Karang dan Ekosistem Terkait di Kabupaten Merauke, Papua. COREMAP-CTI Pusat Penelitian OSeanografi, LIPI. Jakarta.

Syamsuddin, N., Santoso, N., \& Diatin, I. 2019. Inventarisasi Ekosistem Mangrove di Pesisir Randutatah, Kecamatan Paiton, Jawa Timur. Jurnal Pengelolaan Sumberdaya Alam dan Lingkungan, 9(4):893-903. DOI: 10.29244/jpsl.9.4.893-903.

Warfield, A.D. \& Leon, J.X. 2019. Estimating Mangrove Forest Volume Using Terrestrial Laser Scanning and UAV-Derived Structure from Motion. Journal Drones., 3(2):32pages. DOI: $10.3390 /$ drones3020032.

Yuwono, E., Jennerjahn, T.C., Nordhaus, I., Ardli, E.R., Sastranegara, M.H. \& Pribadi, R. 2007. Ecological Status of Segara Anakan, Java, Indonesia, A Mangrove-Fringed Lagoon Affected by Human Activities. Asian Journal of Water, Environment \& Pollution., 4(1):61-70. 